\title{
PENGARUH EFEKTIVITAS PELATIHAN DAN LINGKUNGAN KERJA TERHADAP KOMITMEN KEORGANISASIAN SERTA DAMPAKNYA TERHADAP KINERJA PEGAWAI PADA PT. JASA RAHARJA CABANG JAMBI \\ Anisah $^{1}$
}

\begin{abstract}
This research aims to analyze the influence of the effectiveness of the training and the work environment Against Organizational Commitment And its impact on the performance of Employees At PT Jasa Raharja branch of Jambi, objects in this study are all the employees at PT Jasa Raharja branch of Jambi. Method of data collection that is using a questionnaire and analyzed using descriptive analysis and verifikatif using path analysis. The results of this research will explain there is influence both directly and indirectly from the major variables examined, i.e. the variable effectiveness of the training and employment environment variables as variables independent of the two the dependent variable i.e. organizational commitment and performance.
\end{abstract}

Key words: effectiveness of training, work environment, organizational commitment, performance

\section{PENDAHULUAN}

Usaha meningkatkan kinerja suatu organisasi tidak terlepas dari usaha peningkatan kinerja masing-masing anggotanya. Untuk meningkatkan kinerja masing-masing masing individu tersebut maka diperlukan stimulir, terutama berkaitan erat dengan kebutuhannya. Peningkatan kinerja organisasi akan sangat tergantung dari upaya peningkatan kinerja individu. Upaya dalam meningkatkan kinerja individu pada organisasi juga dilakukan dengan berbagai cara, misalnya melalui pemberian kompensasi yang layak, menciptakan lingkugan kerja yang kondusif, melaksanakan pendidikan dan pelatihan yang efektiv, serta meningkatkan komitmen keorganisasian dari karyawan itu sendiri.

Objek penelitian ini yaitu PT. Jasa Raharja Cab Jambi, yaitu badan usaha milik negara yang bergerak di bidang asuransi sosial kegiatan usahanya yaitu melaksanakan asuransi kecelakaan penumpang alat angkutan umum dan asuransi tanggung jawab menurut hukum terhadap pihak ketiga sebagaimana diatur UU No. 33 dan 34 tahun 1964 berikut peraturan pelaksanaannya. Banyaknya tugas atau pekerjaan yang harus dilaksanakan oleh seorang pegawai di lingkungan kantor PT. Jasa Raharja Cabang Jambi menuntut para pegawainya untuk menguasai tugas dan tanggung jawab serta memacu diri dalam meningkatkan kemampuan kerjanya sehingga sangat dibutuhkan pelatihan dan pengembangan guna meningkatkan komitmen yang berpengaruh terhadap kinerja pegawai pada PT. Jasa Raharja Cabang Jambi

Berdasarkan uraian di atas penulis merasa tertarik untuk melakukan penelitian dengan judul "Pengaruh Efektivitas Pelatihan dan Lingkungan Kerja Terhadap Komitmen Keorganisasian Serta Dampaknya Terhadap Kinerja Pegawai Pada PT. Jasa Raharja Cabang Jambi”

\footnotetext{
${ }^{1}$ Dosen Fakultas Ekonomi Universitas Batanghari
} 
Rumusan masalah dalam penelitian ini adalah : 1) Bagaimana gambaran efektivitas pelatihan, lingkungan kerja, komitmen keorganisasian dan Kinerja Pegawai pada PT. Jasa Raharja Cabang Jambi? 2) Bagaimana pengaruh efektivitas pelatihan dan lingkungan kerja secara simultan terhadap komitmen keorganisasian pada PT. Jasa Raharja Cabang Jambi? 3) Bagaimana pengaruh efektivitas pelatihan dan lingkungan kerja secara parsial terhadap komitmen keorganisasian pada PT. Jasa Raharja Cabang Jambi? 4) Bagaimana pengaruh efektivitas pelatihan dan lingkungan kerja secara simultan terhadap kinerja pegawai pada PT. Jasa Raharja Cabang Jambi? 5) Bagaimana pengaruh efektivitas pelatihan dan lingkungan kerja secara parsial terhadap kinerja pegawai pada PT. Jasa Raharja Cabang Jambi? 6) Bagaimana pengaruh komitmen keorganisasian terhadap kinerja pegawai pada PT. Jasa Raharja Cabang Jambi? 7) Bagaimana pengaruh efektivitas pelatihan dan lingkungan kerja melalui komitmen keorganisasian secara simultan terhadap kinerja pegawai pada PT. Jasa Raharja Cabang Jambi ?

Adapun tujuan dari penelitian ini adalah : 1) Untuk mengetahui bagaimana gambaran efektivitas pelatihan, lingkungan kerja, komitmen keorganisasian dan Kinerja Pegawai pada PT. Jasa Raharja Cabang Jambi. 2) Untuk mengetahui bagaimana pengaruh efektivitas pelatihan dan lingkungan kerja secara simultan terhadap komitmen keorganisasian pada PT. Jasa Raharja Cabang Jambi. 3) Untuk mengetahui bagaimana pengaruh efektivitas pelatihan dan lingkungan kerja secara parsial terhadap komitmen keorganisasian pada PT. Jasa Raharja Cabang Jambi. 4) Untuk mengetahui bagaimana pengaruh efektivitas pelatihan dan lingkungan kerja secara simultan terhadap kinerja pegawai pada PT. Jasa Raharja Cabang Jambi. 5) Untuk mengetahui bagaimana pengaruh efektivitas pelatihan dan lingkungan kerja secara parsial terhadap kinerja pegawai pada PT. Jasa Raharja Cabang Jambi. 6) Untuk mengetahui bagaimana pengaruh komitmen keorganisasian terhadap kinerja pegawai pada PT. Jasa Raharja Cabang Jambi. 7) Untuk mengetahui bagaimana pengaruh efektivitas pelatihan dan lingkungan kerja melalui komitmen keorganisasian secara simultan terhadap kinerja pegawai pada PT. Jasa Raharja Cabang Jambi

\section{Kinerja}

\section{LANDASAN TEORI}

Kinerja berasal dari pengertian performance. Ada pula yang memberikan pengertian performance sebagai hasil kerja atau prestasi kerja. Namun, sebenarnya kinerja mempunyai makna yang lebih luas, bukan hanya hasil kerja, tetapi termasuk bagaimana proses pekerjaan berlangsung. Seiring dengan itu Gomes (2003), memberi istilah performansi untuk kinerja dan mereka membuat pengertian mengenai performansi sebagai berikut: "the record of outcomes produced on a specified job function or activity during a specified time periode", (catatan outcome yang dihasilkan dari fungsi suatu pekerjaan tertentu atau kegiatan selama suatu periode waktu tertentu).

Selanjutnya menurut Resubun (2013) Ada tujuh kriteria yang dapat digunakan untuk mengukur kinerja para pegawai secara individual, yaitu: Kualitas hasil kerja yang dilakukan atau diharapkan dalam bekerja, Produktivitas yang diproduksi atau jumlah kegiatan yang dapat diselesaikan, Tepat waktu, pekerjaan itu bisa selesai pada waktu yang ditentukan dan memaksimalkan waktu untuk kegiatan lain, Efektivitas, yang maksimal dari 
penggunaan sumber daya yang tersedia di organisasi untuk meningkatkan keuntungan dan mengurangi kerugian, Self-reliance, yang mampu melakukan tugasnya tanpa bantuan untuk menghindari hasil yang buruk, Komitmen bekerja, adalah janji antara pekerja dan organisasi, Tanggung jawab dari karyawan untuk organisasi.

Gomes (2003) juga mengungkapkan beberapa dimensi atau criteria yang perlu mendapat perhatian dalam mengukur kinerja, antara lain : Kuantitas Kerja, Kualitas Kerja, Pengetahuan Kerja, Kreatifitas, Kerjasama, Kehandalan, Inisiatif, Kualitas Personal,

\section{Komitmen Keorganisasian}

Allen \& Meyer (1990) mengungkapkan tiga pendekatan mengenai komitmen, yaitu afektif, normatif dan kontinuan, apabila dalam diri karyawan melekat komitmen afektif, komitmen normatif dan komitmen kontinuan, maka ini akan berdampak terhadap kinerja perusahaan. Robbins \& Judge (2009) juga mengemukakan ada tiga tema yang sama dalam mendefinisikan komitmen kerja atau mengukur komitmen, antara lain sebagai berikut : Komitmen Afektif yaitu keterikatan emosional, identifikasi dan keterlibatan dalam suatu organisasi, Komitmen Kontinuan yaitu komitmen individu yang didasarkan pada pertimbangan tentang apa yang harus dikorbankan bila akan meninggalkan organisasi. Komitmen Normatif yaitu keyakinan individu tentang tanggung jawab terhadap organisasi. Individu tetap tinggal pada suatu organisasi karena merasa wajib untuk loyal pada organisasi tersebut.

\section{Efektivitas Pelatihan}

Samsudin (2005) menyatakan bahwa efektivitas adalah "Kapasitas suatu organisasi untuk memperoleh dan memanfaatkan sumber daya yang berharga dengan sepandai mungkin dalam mengejar tujuan operasional. Selain dari itu Devi \& Shaik (2012) mengungkapkan bahwa efektivitas adalah kemampuan untuk menghasilkan efek yang dikehendaki.

Menurut Mondy (2008), untuk mengukur efektivitas suatu program pelatihan dapat dievaluasi berdasarkan informasi yang diperoleh pada beberapa tingkatan: Opini Peserta Pelatihan yaitu mengevaluasi program pelatihan dan pengembangan dengan menanyakan opini para peserta merupakan pendekatan yang memberikan respons dan saran untuk perbaikan; tingkat Pembelajaran yaitu untuk mengetahui seberapa jauh para peserta menguasai kensep-konsep, pengetahuan dan keterampilan-keterampilan yang diberikan selama pelatihan; perubahan perilaku yaitu menilai dari para peserta sebelum dan sesudah pelatihan; pencapaian tujuan pelatihan yaitu untuk menguji dampak pelatihan terhadap kelompok kerja atau organisasi secara keseluruhan.

\section{Lingkungan Kerja}

Nitisemito (2000: 67) mendefinisikan bahwa lingkungan kerja adalah segala sesuatu yang ada disekitar para pekerja yang dapat mempengaruhi dirinya dalam menjalankan tugas-tugas yang diembankan. Selanjutnya Sedarmayanti (2001: 97) menyatakan bahwa secara garis besar, jenis lingkungan kerja terbagi menjadi 2 yakni (a) lingkungan kerja fisik, dan (b) lingkungan keija non fisik Lingkungan kerja fisik diantaranya adalah: penerangan/cahaya, temperatur/suhu udara, kelembaban, sirkulasi udara, kebisingan, setaran inekanis, bau tidak sedap, tata warna, dekorasi, musik dan keamanan di tempat kerja. 
Berdasarkan pembatasan diatas, dapat ditafsirkan lingkungan kerja meliputi (Nitisemito, 2000): Kondisi bangunan dan ruang, lokasi atau letak tempat kerja (Perusahaan), fasilitas kerja, fasilitas kebersihan, tata tertib bagi pekerja, rekan kerja, keamanan kerja, kekeluargaan

\section{Kerangka Pemikiran}

Secara ringkas kerangka pemikiran dalam penelitian ini dapat digambarkan sebagai berikut :

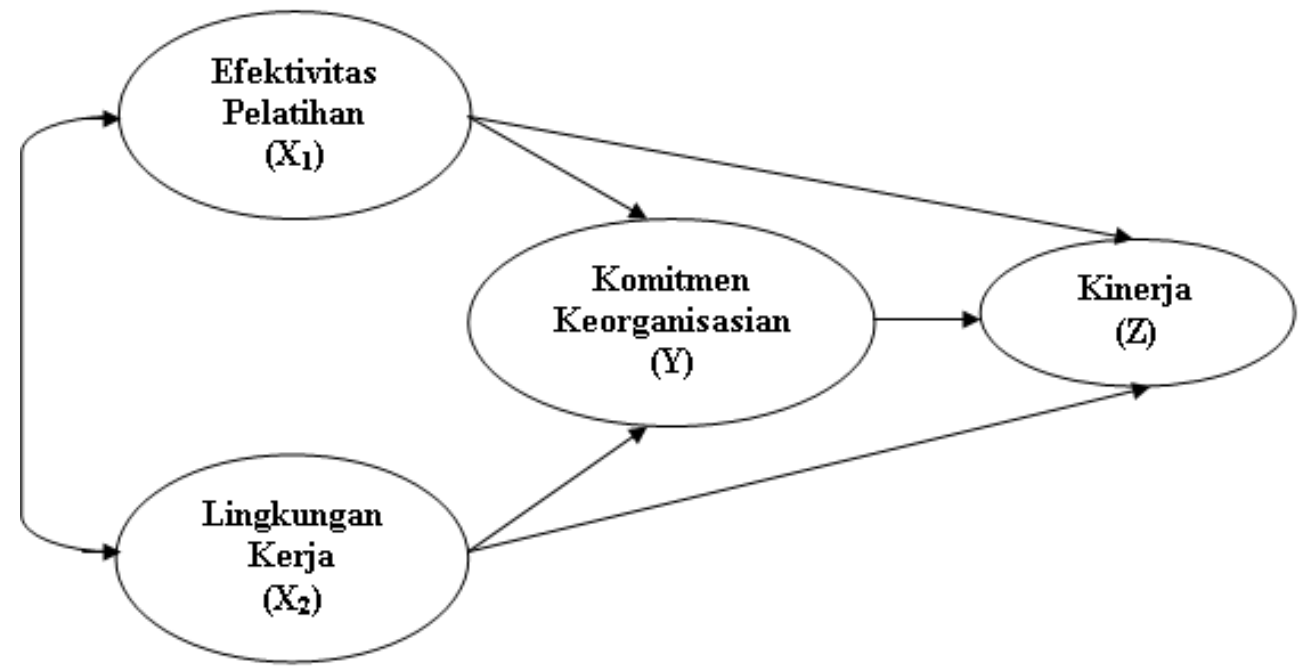

Gambar Kerangka Pemikiran

Keterangan :

$\mathrm{X} 1$ : Efektivitas Pelatihan

$\mathrm{X} 2$ : Lingkungan Kerja

$\mathrm{Y}:$ Komitmen Keorganisasian

$\mathrm{Z}:$ Kinerja

\section{Hipotesis Penelitian}

Hipotesis dalam penelitian ini adalah :

a. Diduga efektivitas pelatihan, lingkungan kerja, komitmen keorganisasian dan Kinerja Pegawai pada PT. Jasa Raharja Cabang Jambi sudah dalam kategori baik

b. Diduga efektivitas pelatihan dan lingkungan kerja berpengaruh positif dan signifikan secara simultan terhadap komitmen keorganisasian pada PT. Jasa Raharja Cabang Jambi

c. Diduga efektivitas pelatihan dan lingkungan kerja berpengaruh positif dan signifikan secara parsial terhadap komitmen keorganisasian pada PT. Jasa Raharja Cabang Jambi

d. Diduga efektivitas pelatihan dan lingkungan kerja berpengaruh positif dan signifikan secara simultan terhadap kinerja pegawai pada PT. Jasa Raharja Cabang Jambi

e. Diduga efektivitas pelatihan dan lingkungan kerja berpengaruh positif dan signifikan secara parsial terhadap kinerja pegawai pada PT. Jasa Raharja Cabang Jambi

f. Diduga komitmen keorganisasian berpengaruh positif dan signifikan terhadap kinerja pegawai pada PT. Jasa Raharja Cabang Jambi 
g. Diduga efektivitas pelatihan dan lingkungan kerja melalui komitmen keorganisasian berpengaruh positif dan signifikan secara simultan terhadap kinerja pegawai pada PT. Jasa Raharja Cabang Jambi

\section{Desain Penelitian}

\section{METODE PENELITIAN}

Penelitian ini adalah berjenis penelitian survei dengan tujuan eksplanatif. Penelitian ekspalanatif menemukan penjelasan mengapa suatu kejadian atau gejala terjadi, hasil akhir dari tujuan ini adalah gambaran mengenai hubungan sebab akibat.

\section{Jenis dan Sumber Data}

Sumber data dalam penelitian adalah subyek asal data dapat diperoleh. Menurut Usman dan Akbar (2012), Adapun sumber penelitian yaitu sumber data primer dan sumber data skunder. Penulis dalam meneliti menggunakan kedua sumber data ini. Data primer diperoleh menggunakan metode Survei dengan tehnik pengumpulan data berupa kuesioner. Kemudian data sekunder diperoleh berupa data internal PT. Jasa Raharja Cab. Jambi yang berbentuk data pelatihan dan sebagainya serta data eksternal yang berupa buku-buku yang berhubungan dengan penelitian.

\section{Metode Pengumpulan Data}

Penulis menggunakan tehnik pengumpulan data sebagai berikut : library research (studi kepustakaan), dan field research (studi lapangan), adapun studi lapangan penulis langsung terjun ke lapangan dengan cara menyebarkan kuesioner terhadap responden penelitian dan wawancara.

\section{Teknik Pengambilan Sampel}

Teknik pengambilan sampel dalam penelitian ini yaitu menggunakan metode sensus, dimana yang menjadi responden dalam penelitian ini adalah seluruh pegawai pada PT. Jasa Raharja Cab. Jambi.

\section{Metode Analisis}

Untuk menjawab tujuan penelitian ke satu serta untuk menginterprestasikan data dan informasi dalam penelitian penulis menggunakan analisis deskriptif yaitu dengan menggunakan rentang skala. Rentang skala yang digunakan dari hasil perumusan yakni :

\begin{aligned} & \hline \multicolumn{1}{l}{ Skor } \multicolumn{1}{c}{ Kriteria } \\ & \hline $43-77,3$ Sangat Tidak Baik. \\ & $77,4-111,7$ Tidak Baik. \\ & $111,8-146,1$ Cukup Baik \\ & $146,2-180,5$ Baik \\ & $180,6-215$ Sangat Baik \\ & \hline\end{aligned}

Untuk menjawab tujuan kedua sampai dengan tujuan ke tujuh penulis menggunakan analisis verivikatif dengan menggunakan path analysis (analisis jalur).

Berikut adalah struktur lengkap path analysis (pengaruh efektivitas pelatihan dan lingkungan kerja terhadap komitmen keorganisasian serta pengaruhnya terhadap kinerja pegawai PT. Jasa Raharja Cab. Jambi) : 


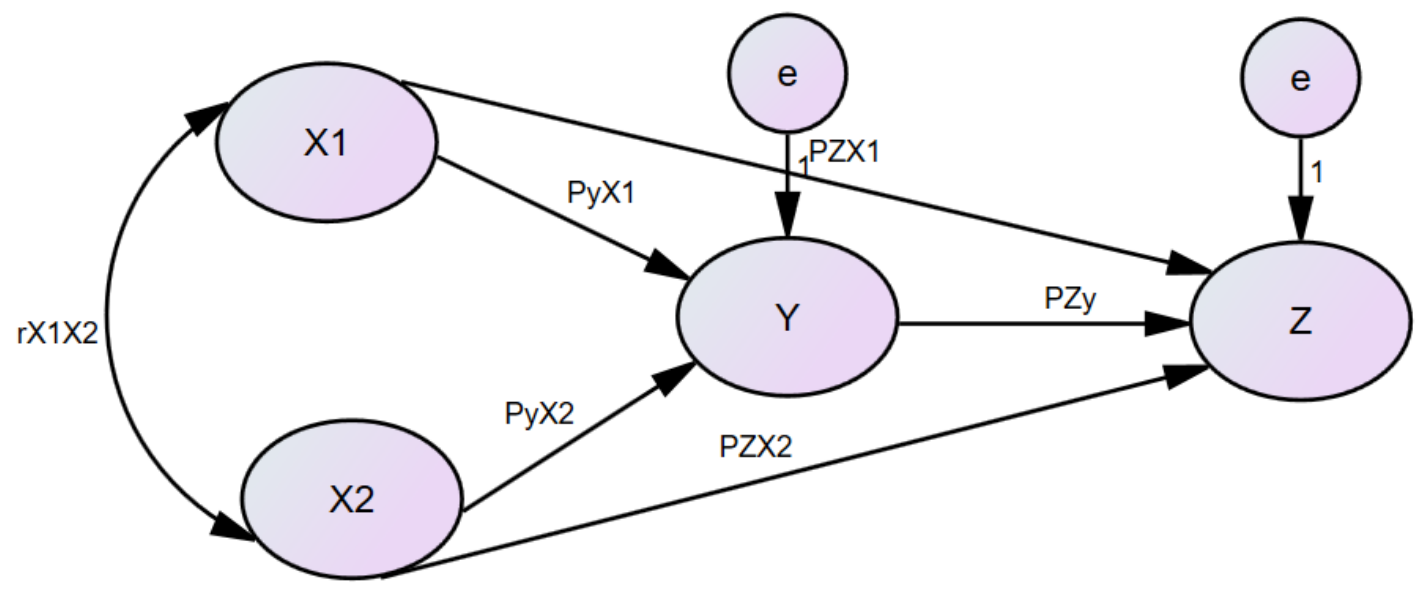

Gambar Hubungan Struktural $X_{1}, X_{2}$ Terhadap $Y$ dan $Z$

\section{Analisis Deskriptif}

\section{HASIL DAN PEMBAHASAN}

\section{a. Variabel Efektivitas Pelatihan}

Hasil analisis deskriptif data variabel efektivitas pelatihan sebagai salah satu variabel yang diukur melalui analisis deskriptif dengan menggunakan skala likert yang dilihat dari tingkat rata-rata dan tingkat capaian responden menunjukkan skor rata rata 148,3 hal ini menunjukkan bahwa efektivitas pelatihan pada PT. Jasa Raharja Cab. Jambi sudah tergolong baik.

\section{b. Variabel Lingkungan Kerja}

Hasil analisis deskriptif data variabel lingkungan kerja sebagai salah satu variabel yang diukur melalui analisis deskriptif dengan menggunakan skala likert yang dilihat dari tingkat rata-rata dan tingkat capaian responden menunjukkan skor rata rata 149,4 hal ini menunjukkan bahwa lingkungan kerja pada PT. Jasa Raharja Cab. Jambi sudah tergolong baik.

\section{c. Variabel Komitmen Keorganisasian}

Hasil analisis deskriptif data variabel komitmen keorganisasian sebagai salah satu variabel yang diukur melalui analisis deskriptif dengan menggunakan skala likert yang dilihat dari tingkat rata-rata dan tingkat capaian responden menunjukkan skor rata rata 181,7 hal ini menunjukkan bahwa komitmen keorganisasian pada PT. Jasa Raharja Cab. Jambi tergolong sangat baik.

\section{d. Variabel Kinerja}

Hasil analisis deskriptif data variabel kinerja sebagai salah satu variabel yang diukur melalui analisis deskriptif dengan menggunakan skala likert yang dilihat dari tingkat rata-rata dan tingkat capaian responden menunjukkan skor rata rata 189,3 hal ini menunjukkan bahwa kinerja pada PT. Jasa Raharja Cab. Jambi tergolong sangat baik.

\section{Pengujian Instrumen Penelitian}

\section{a. Uji Validitas}

Berdasarkan hasil analisis dari ke empat variabel-variabel penelitian yang telah dibahas, adapun pengujian validitas menggunakan $r$ Product Moment maka dapat disimpulkan bahwa seluruh item pertanyaan dalam 
penelitian ini valid hal ini ditunjukkan dengan lebih besarnya $r$ hitung masing masing item pertanyaan daripada nilai $r$ tabel.

\section{b. Uji Relabilitas}

Dari hasil reliability analysis (lampiran) diperoleh koefisien varians (Alpha) untuk setiap variabel sebagai berikut :

\section{Hasil Uji Reliabilitas Instrumen Terhadap Variabel Efektivitas Pelatihan, Lingkungan Kerja, Komitmen Keorganisasian,} Kinerja Pegawai

\begin{tabular}{lccc}
\hline \multicolumn{1}{c}{ Kuesioner } & $\begin{array}{c}\text { Koefisien } \\
\text { Reliabilitas }\end{array}$ & r tabel & Keterangan \\
\hline Efektivitas Pelatihan & 0,887 & 0,268 & Reliabel \\
Lingkungan Kerja & 0,878 & 0,268 & Reliabel \\
Komitmen Keorganisasian & 0,755 & 0,268 & Reliabel \\
Kinerja Pegawai & 0,879 & 0,268 & Reliabel \\
\hline
\end{tabular}

Sumber : Data Olahan Melalui Program SPSS 22.0

\section{Path Analysis (Analisis Jalur)}

Besarnya pengaruh langsung dari suatu variabel eksogenus terhadap variabel endogenus, dinyatakan oleh besarnya nilai numerik koefesien jalur (path coefficient) dari eksogenus ke endogenus seperti pada gambar berikut :

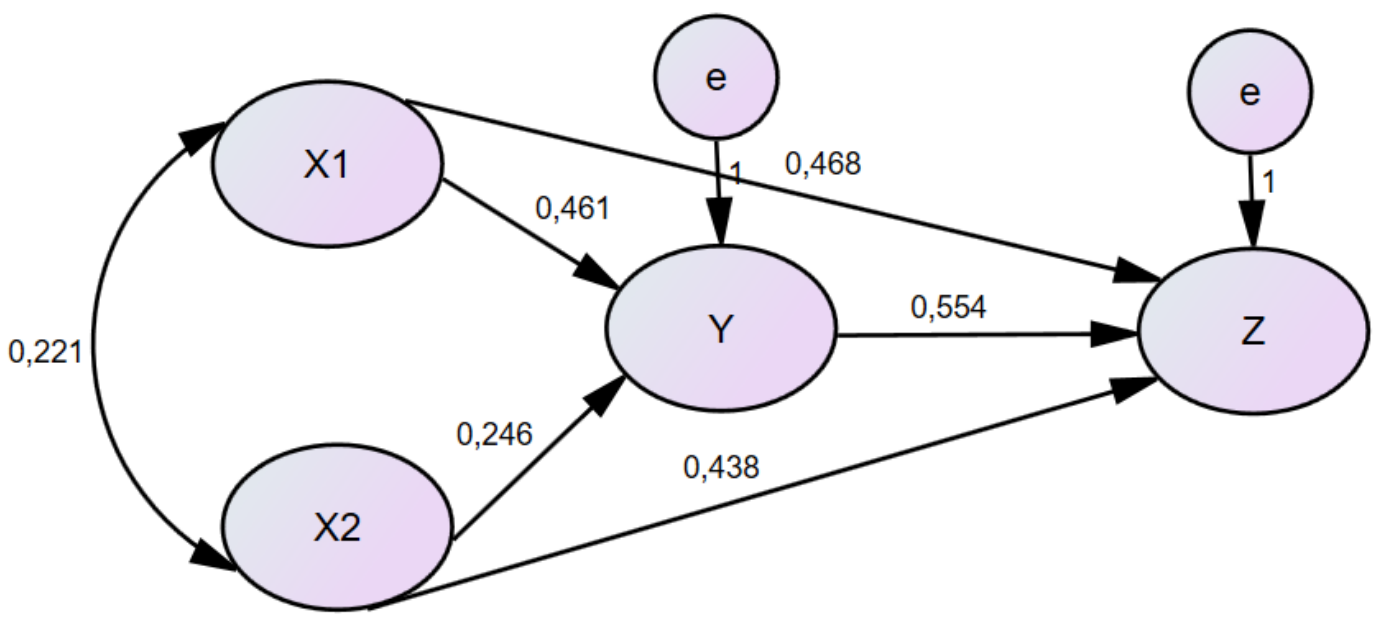

Koefisien Jalur $X_{1}, X_{2}$ Terhadap Y dan Z Data diolah menggunakan SPSS dan Amos Ver.22

\section{Pengujian Hipotesis}

\section{a. Uji Hipotesis Pertama}

Pengujian hipotesis pertama didasarkan pada analisis deskriptif yang telah dikemukakan sebelumnya, pada pengujian tersebut telah ditarik kesimpulan bahwa hipotesis diterima, masing masing variabel penelitian yaitu efektivitas pelatihan dan lingkungan kerja sudah tergolong baik, komitmen keorganisasian dan kinerja tergolong sangat baik.

b. Uji Hipotesis Kedua

Pengujian hipotesis ketiga akan diuji dengan uji $F$ (simultan). hipotesis diterima. Hal ini terlihat dari perhitungan SPSS dibawah ini 
dimana F-hitung > F-tabel $(12,157>3,18)$ maka efektivitas pelatihan dan lingkungan kerja berpengaruh signifikan terhadap komitmen keorganisasian.

Adapun analisis dari pengaruh langsung dan tidak langsung dan total pengaruh antar variabel secara manual yaitu :

Langsung $\mathrm{X} 1 \rightarrow \mathrm{Y}=\rho \mathrm{X}_{1}$. $\rho \mathrm{X}_{1}$

$$
=0,2125(21,25 \%)
$$

Tidak Langsung $\mathrm{X} 1 \rightarrow \mathrm{Y} \Omega \mathrm{X}_{2}=\rho \mathrm{y} \mathrm{X}_{1} \cdot \mathrm{rX}_{1} \mathrm{X}_{2} \cdot \rho \mathrm{y} \mathrm{X}_{2}$

$=0,0250(2,50 \%)$

Langsung $\mathrm{X}_{2} \rightarrow \mathrm{Y}=\rho \mathrm{y} \mathrm{X}_{2}$. $\rho \mathrm{y} \mathrm{X}_{2}$

$=0,0605(6,05 \%)$

Total Pengaruh Langsung $=0,2125+0,0605$

$=0,273(27,3 \%)$

Total Pengaruh Tidak Langsung $=0,0250+0,0250$

$=0,05(5 \%)$

\section{c. Uji Hipotesis Ketiga}

Pengujian hipotesis ketiga akan diuji dengan uji t (parsial). Hipotesis diterima, hal ini terllihat dari perhitungan menggunakan SPSS dimana thitung > t-tabel yaitu nilai t-hitung variabel Efektivitas Pelatihan (3,900 > $1,675)$ dan nilai t-hitung variabel lingkungan kerja $(2,082>1,675)$ maka efektivitas pelatihan dan lingkungan kerja secara parsial berpengaruh positif dan signifikan terhadap komitmen keorganisasian.

\section{d. Uji Hiptesis Keempat}

Pengujian hipotesis keempat akan menguji dengan uji $\mathrm{F}$ (simultan). Hipotesis diterima, hal ini terlihat dengan perhitungan SPSS dimana Fhitung > F-tabel $(18,008>3,18)$ maka efektivitas pelatihan dan lingkungan kerja berpengaruh signifikan terhadap kinerja pegawai.

Adapun analisis dari pengaruh langsung dan tidak langsung dan total pengaruh antar variabel secara manual yaitu :

Langsung $\mathrm{X} 1 \rightarrow \mathrm{Z}=\rho \mathrm{z} \mathrm{X}_{1}$. $\rho \mathrm{z} \mathrm{X}_{1}$

$=0,2190(21,9 \%)$

Tidak Langsung $\mathrm{X} 1 \rightarrow \mathrm{Z} \Omega \mathrm{X}_{2}=\rho \mathrm{z} \mathrm{X}_{1} \cdot \mathrm{rX}_{1} \mathrm{X}_{2} \cdot \rho \mathrm{z} \mathrm{X}_{2}$

$=0,0361(3,61 \%)$

Langsung $\mathrm{X} 2 \rightarrow \mathrm{Z}=\rho \mathrm{z} \mathrm{X}_{2} . \rho \mathrm{z} \mathrm{X}_{2}$

$=0,1918(19,18 \%)$

Total Pengaruh Langsung $=0,2190+0,1918$

$=0,4108(41,08 \%)$

Total Pengaruh Tidak Langsung $=0,0361+0,0361$

$=0,0722(7,22 \%)$

\section{e. Uji Hipotesis Kelima}

Pengujian hipotesis kelima akan diuji dengan uji $\mathrm{t}$ (parsial). Hipotesis diterima, hal ini terllihat dari perhitungan menggunakan SPSS dimana thitung > t-tabel yaitu nilai t-hitung variabel Efektivitas Pelatihan (4,259 > $1,675)$ dan nilai t-hitung variabel lingkungan kerja $(3,183>1,675)$ maka efektivitas pelatihan dan lingkungan kerja secara parsial berpengaruh positif dan signifikan terhadap komitmen keorganisasian.

\section{f. Uji Hipotesis Keenam}

Pengujian hipotesis keenam akan diuji dengan uji $\mathrm{t}$ (parsial). Hipotesis diterima, hal ini terllihat dari perhitungan menggunakan SPSS dimana thitung > t-tabel yaitu nilai t-hitung variabel komitmen keorganisasian (4,794 
$>1,674)$ maka komitmen keorganisasian berpengaruh signifikan terhadap kinerja pegawai.

Adapun analisis dari pengaruh langsung dan tidak langsung dan total pengaruh antar variabel secara manual yaitu :

Langsung $\mathrm{Y} \rightarrow \mathrm{Z}=\rho \mathrm{zy}$. $\rho \mathrm{zy}$

$=0,3069(30,69 \%)$

\section{g. Uji Hipotesis Ketujuh}

untuk menjawab berapa besar pengaruh langsung X1 dan X2 secara simultan terhadap $\mathrm{Z}$ melalui Y adalah

1) Pengaruh langsung

$=\left(\mathrm{P}_{\mathrm{ZX} 1}\right)\left(\mathrm{P}_{\mathrm{YX} 1}\right)\left(\mathrm{P}_{\mathrm{ZY}}\right)+\left(\mathrm{P}_{\mathrm{ZX} 2}\right)\left(\mathrm{P}_{\mathrm{YX} 2}\right)\left(\mathrm{P}_{\mathrm{ZY}}\right)$

$=(0,468)(0,461)(0,554)+(0,438)(0,246)(0,554)$

$=(0,1195)+(0,0596)$

$=0,1791$ atau $17,9 \%$

2) Pengaruh tidak langsung

$=\left(\mathrm{P}_{\mathrm{ZX} 1}\right)\left(\mathrm{P}_{\mathrm{YX} 1}\right)\left(\mathrm{r}_{\mathrm{X} 1 \mathrm{X} 2}\right)\left(\mathrm{P}_{\mathrm{YX} 2}\right)\left(\mathrm{P}_{\mathrm{ZY}}\right)+\left(\mathrm{P}_{\mathrm{ZX} 2}\right)\left(\mathrm{P}_{\mathrm{YX} 2}\right)\left(\mathrm{r}_{\mathrm{X} 1 \mathrm{X} 2}\right)\left(\mathrm{P}_{\mathrm{YX} 1}\right)\left(\mathrm{P}_{\mathrm{ZY}}\right)$

$=(0,468)(0,461)(0,221)(0,246)(0,554)+(0,438)(0,246)(0,221)$

$(0,461)(0,554)$

$=0,0064+0,0060$

$=0,0124$ atau $1,24 \%$

3) Total pengaruh

$=$ Pengaruh langsung + Pengaruh tidak langsung

$=0,1791+0,0124$

$=0,1915$ atau $19,15 \%$

Dari perhitungan di atas dapat ditarik kesimpulan bahwa hipotesis diterima, hal ini terlihat dari variabel efektivitas pelatihan dan lingkungan kerja melalui komitmen secara simultan berpengaruh signifikan terhadap kinerja pegawai pada PT. Jasa Raharja Cab. Jambi

\section{Simpulan}

\section{SIMPULAN DAN SARAN}

Berdasarkan hasil pembahasan penelitian pada bab sebelumnya maka dapat ditarik beberapa simpulan sebagai berikut:

1. Efektivitas pelatihan, lingkungan kerja, komitmen keorganisasian serta kinerja pegawai pada PT. Jasa Raharja Cab. Jambi masih dalam tergolong baik,

2. Efektivitas pelatihan dan lingkungan kerja secara simultan berpengaruh positif dan signifikan terhadap komitmen keorganisasian pegawai pada PT. Jasa Raharja Cab. Jambi.

3. Efektivitas pelatihan dan lingkungan kerja secara parsial berpengaruh positif dan signifikan terhadap komitmen keorganisasian pegawai pada PT. Jasa Raharja Cab. Jambi.

4. Efektivitas pelatihan dan lingkungan kerja secara simultan berpengaruh positif dan signifikan terhadap kinerja pegawai pada PT. Jasa Raharja Cab. Jambi.

5. Efektivitas pelatihan dan lingkungan kerja secara parsial berpengaruh positif dan signifikan terhadap kinerja pegawai pada PT. Jasa Raharja Cab. Jambi.

6. Komitmen keorganisasian berpengaruh positif dan signifikan terhadap kinerja pegawai PT. Jasa Raharja Cab. Jambi.

7. Efektivitas pelatihan dan lingkungan kerja melalui komitmen secara simultan berpengaruh positif dan signifikan terhadap kinerja pegawai pada PT. Jasa 


\section{Saran}

Raharja Cab. Jambi.

Mengingat begitu besarnya pengaruh efektivitas pelatihan dan lingkungan kerja terhadap komitmen keorganisasian pegawai serta dampaknya terhadap kinerja pegawai, PT. Jasa Raharja Cab. Jambi harus tetap memperhatikan perbaikan terhadap efektivitas pelatihan, lingkungan kerja, komitmen agar kinerja pegawai PT. Jasa Raharja Cab. Jambi akan terus membaik ke depannya.

\section{DAFTAR PUSTAKA}

Allen, Natalie J., Meyer Jhon P., (1990), The measurement and antecedents of affective, continuance and normative commitment to the organization, Journal of Occupational Psychology, The British Psychological Society

Devi, R,V., Shaik, Nagurvali. (2012), Evaluating training \& development effectiveness - A measurement model, Asian Journal Of Management Research, Volume 2 Issue 1

Gomes, Faustino Cardoso., (2003), Manajemen Sumber Daya Manusia, Penerbit Andi OFFSET Yogykarta

Mathis, Robert L., Jackson, John H., (2006). Human Resource Management (Manajemen Sumber Daya Manusia), Edisi 10, Penerbit : Salemba Empat

Mondy, R. Wayne., (2008), Manajemen Sumber Daya Manusia, Jilid 1 Edisi 10, Alih Bahasa Bayu Airlangga, Penerbit : Erlangga

Robbins, Stephen P., Judge, Timothy A (2009), Organizational Behaviour, Global Edition, Fourteenth Edition, Pearson

Resubun, Y., Hadiwidjojo, D., Rofyati., Djazuli. (2013), Factors Affecting Employee Performance In Regional Owned Enterprises Papua ProvinceIndonesia, Interdisciplinary Journal Of Contemporary Research In Business, Vol.5, No.6

Usman, Husaini., Akbar, Purnomo Setiady (2012), Pengantar Statistika, Edisi Kedua, Penerbit Bumi Aksara 